\title{
Subjects with Discordant Airways Obstruction: Lost between Spirometric Definitions of COPD
}

\author{
Bernd Lamprecht, ${ }^{1}$ Lea Schirnhofer, ${ }^{1}$ Bernhard Kaiser, ${ }^{1}$ Sonia A. Buist, ${ }^{2}$ \\ David M. Mannino, ${ }^{3}$ and Michael Studnicka ${ }^{1}$ \\ ${ }^{1}$ Department of Pulmonary Medicine, Paracelsus Private Medical University of Salzburg, 5020 Salzburg, Austria \\ ${ }^{2}$ Department of Pulmonary and Critical Care Medicine, Oregon Health and Science University, Portland, OR 97239, USA \\ ${ }^{3}$ Department of Preventive Medicine and Environmental Health, University of Kentucky, Lexington, KY 40536, USA
}

Correspondence should be addressed to Bernd Lamprecht, b.lamprecht@salk.at

Received 4 September 2010; Accepted 8 January 2011

Academic Editor: Irwin Reiss

Copyright ( 92011 Bernd Lamprecht et al. This is an open access article distributed under the Creative Commons Attribution License, which permits unrestricted use, distribution, and reproduction in any medium, provided the original work is properly cited.

Background. Since the FEV1/FVC ratio declines with age, using the fixed ratio of 0.70 leads to overdiagnosis of COPD in older populations and underdiagnosis among young adults. Objective. To evaluate whether discordant obstructive cases (FEV1/FVC $<$ 0.70 but $\geq$ LLN) are a healthy population or have clinical features that would place them at increased risk. Methods. We used post-bronchodilator spirometry data from the population-based Austrian Burden of Obstructive Lung Disease (BOLD) study. Those with post-bronchodilator FEV1/FVC ratio $<$ LLN and $<0.70$ were defined as concordant obstructive cases. Participants with post-bronchodilator FEV1/FVC ratio $\geq$ LLN but $<0.70$ were defined as discordant obstructive cases. Results. Discordant obstructive cases were more likely to be older, male and never-smokers. Additionally they had less respiratory symptoms and less severe impairment of FEV1. However, discordant obstructive cases reported significantly more often a diagnosis of heart disease than subjects with normal lung function $(27.2 \%$ vs $7.3 \%, P=.015)$. Conclusion. The clinical profile of discordant obstructive cases includes potentially important comorbid disease.

\section{Introduction}

Lung function measurements are recommended as essential for diagnosing COPD and helpful for grading its severity $[1]$.

According to current GOLD guidelines [2], chronic obstructive pulmonary disease is defined as airflow limitation with a postbronchodilator FEV1/FVC ratio below $70 \%$.

On the one hand, these criteria have simplified the diagnosis of COPD and have helped to improve the awareness of this disease. But on the other hand, the use of a fixed threshold to define airways obstruction is associated with some extent of misclassification. Since the FEV1/FVC ratio declines with age, there is a risk of overdiagnosis of COPD among healthy elderly people [3]. Because of this misclassification problem, the American Thoracic Society/
European Respiratory Society guidelines [4] continue to officially recommend an interpretative algorithm that uses the 5th percentile lower limit of normal (LLN), which is agespecific and declines with age, to define pulmonary function abnormalities.

For this study, we analyzed postbronchodilator spirometry data of an Austrian population-based survey in adults aged 40 years and over. We compared the fixed ratio with the lower limit of normal as a diagnostic criterion for nonreversible airways obstruction. We tested the hypothesis that discordant obstructive cases (FEV1/FVC $<0.70$ and $\geq$ LLN) are a healthy population (i.e., they are elderly, asymptomatic subjects without the presence of known risk factors for chronic airways obstruction) or whether these inbetween cases might represent subjects at risk who should be followed carefully. 


\section{Methods}

2.1. Study Population. The study population consisted of participants of the Austrian Burden of Obstructive Lung Disease (BOLD) study [5]. In this study, a gender-stratified random sample of the inhabitants of Salzburg County, aged 40 years and over, was surveyed. Of the 2,200 individuals (1,100 men and 1,100 women) whom we attempted to contact, 1,258 (60\%) completed the full protocol and had spirometry findings that met ATS quality control criteria (see below). These individuals constitute the primary sample for this analysis. The study was approved by the local Ethics Committee of Salzburg County, and all participants gave written informed consent.

2.2. Study Measures. Spirometry was done according to American Thoracic Society (ATS) criteria [6] by trained and certified technicians using the NDD Easy One spirometer with participants in a seated position. Separate measurements were made before and at least 15 minutes after two puffs of salbutamol $(200 \mu \mathrm{g})$ metered dose inhaler, administered using a Volumatic spacer. Spirometry data were sent electronically to the Pulmonary Function Quality Control Centre in Salt Lake City, Utah, USA, where each spirogram was reviewed and graded using ATS guidelines [6].

Only spirograms that met ATS acceptability and reproducibility criteria were included; at least three trials, two acceptable (free from artefact, sudden stops, and back extrapolated volumes greater than $5.0 \%$ of FVC) and reproducible (difference between largest and second largest values is less than $200 \mathrm{~mL}$ ) tests for both the forced expiratory volume in one-second $\left(\mathrm{FEV}_{1}\right)$ and the forced vital capacity (FVC). Study technicians were continuously monitored. When a technician's quality score dropped below a preset level, he/she had to stop testing and be retrained and recertified.

2.3. Questionnaire Data. The BOLD questionnaires included information on respiratory symptoms, risk factors for COPD, comorbidities, and respiratory diagnoses, and were administered by a trained and certified staff.

2.4. Definitions. Nonreversible "airways obstruction" was defined either as a postbronchodilator FEV1/FVC ratio below the lower limit of normal (LNN) or an FEV1/FVC ratio below 0.70 (according to GOLD criteria).

The NHANES III reference equations [7] were used to calculate predicted values and LLNs for FEV1, FVC, and FEV1/FVC. The Lower limit of normal (LLN) is based on the lower fifth percentile of the index.

In the presence of an abnormal FEV1/FVC ratio, "severity of airway obstruction" was graded as follows, possible normal variant (FEV1 > 100\% predicted), mild (FEV1 70-100\% predicted), moderate (FEV1 $50-70 \%$ predicted), and severe (FEV $1<50 \%$ predicted).

Participants whose postbronchodilator FEV1/FVC ratio was below both the LLN and the fixed ratio of 0.70 were defined as "concordant obstructive cases".
TABle 1: Population characteristics and postbronchodilator lung function data $(n=1258)$.

\begin{tabular}{lcc}
\hline & Male & Female \\
\hline Subjects, $n(\%)$ & $685(54.5 \%)$ & $573(45.5 \%)$ \\
Age distribution yrs, $n(\%)$ & & \\
$40-50$ & $206(30.1 \%)$ & $183(31.9 \%)$ \\
$51-60$ & $202(29.5 \%)$ & $175(30.5 \%)$ \\
$61-70$ & $169(24.7 \%)$ & $136(23.7 \%)$ \\
$71-80$ & $83(12.1 \%)$ & $57(10.0 \%)$ \\
$81+$ & $25(3.6 \%)$ & $22(3.9 \%)$ \\
\hline Body mass index $\left[\mathrm{kg} /\left(\mathrm{m}^{2}\right)\right]$, & $26.7(0.14)$ & $26.1(0.20)$ \\
mean (SD) & $4.5(97.5 \%)$ & $3.4(100.6 \%)$ \\
FVC (L), mean $(\%$ pred.) & $3.4(95.0 \%)$ & $2.5(95.9 \%)$ \\
FEV1 (L), mean (\%pred.) & $74.1(97.6 \%)$ & $74.5(95.5 \%)$ \\
FEV1/FVC\%, mean (\%pred.) & &
\end{tabular}

Participants who had a postbronchodilator FEV1/FVC ratio above the LLN but below the fixed ratio of 0.70 were defined as "discordant obstructive cases".

"Restrictive lung function" was defined as postbronchodilator FVC $<80 \%$ predicted and a FEV1/FVC $>70 \%$.

"Doctor-diagnosed COPD" was defined as self-reported physician's diagnosis of chronic bronchitis, emphysema, or COPD.

"Ever smoking" (current or former smoking) was defined as smoking more than 20 packs of cigarettes in a lifetime or more than 1 cigarette/day for a year. "Never smoking" was defined as smoking less than 20 packs of cigarettes in a lifetime.

Additional measures evaluated included self-report of respiratory symptoms for "cough" (Do you usually cough when you don't have a cold?), "phlegm" (Do you usually bring up phlegm from your chest, or do you usually have phlegm in your chest that is difficult to bring up when you don't have a cold?), and "dyspnea" (Are you troubled by shortness of breath when hurrying on the level or walking up a slight hill?); and "self-reported physician diagnosis" of asthma, tuberculosis, heart disease, hypertension, diabetes, and stroke.

2.5. Statistical Analysis. Sensitivity and specificity of FEV1/FVC < LLN for diagnosing airway obstruction defined by FEV1/FVC $<0.70$ were calculated using $2 \times 2$ tables. Statistical significance of differences was evaluated using the chi-square test and the nonparametric Wilcoxon test. All statistical analyses were done with SAS 8.2 (SAS Institute, Inc., Cary, NC).

\section{Results}

Of the 1349 participants with postbronchodilator spirometry, 1258 (93\%) met the quality control criteria and were included in this analysis. Population characteristics and postbronchodilator lung function data of the study population $(n=1258)$ are shown in Table 1. 
TABLE 2: Airways obstruction defined by postbronchodilator FEV1/ FVC $<0.70$ and FEV $1 /$ FVC $<$ LLN.

\begin{tabular}{lcc}
\hline & $\begin{array}{c}\text { FEV1/FVC }<0.70 \\
(n=304)\end{array}$ & $\begin{array}{c}\text { FEV1/FVC } \geq 0.70 \\
(n=954)\end{array}$ \\
\hline $\begin{array}{l}\text { FEV1/FVC }<\text { LLN } \\
(n=199)\end{array}$ & $192(63.2 \%)$ & $7(0.7 \%)$ \\
$\begin{array}{l}\text { FEV1/FVC } \geq \text { LLN } \\
(n=1059)\end{array}$ & $112(36.8 \%)$ & $947(99.3 \%)$ \\
\hline
\end{tabular}

Applying the current GOLD criteria (FEV1/FVC $<0.70)$ to postbronchodilator spirometry, the prevalence of COPD GOLD stage I or higher in our population-based sample of adults aged 40 years and over was $24.2 \%$. In contrast to this, utilization of the lower limit of normal as a threshold for the FEV1/FVC ratio $($ FEV1/FVC $<$ LLN) demonstrated a prevalence of $15.3 \%$. Prevalence of doctor-diagnosed COPD (reported physicians diagnosis of COPD, emphysema, or chronic bronchitis) was 5.6\%.

Figure 1 shows the declining FEV1/FVC ratio by age in the study group without airways obstruction $(n=1059$, FEV1/FVC > LLN). The prevalence of COPD by diagnostic definition and age group is illustrated in Figure 2. Sensitivity and specificity of the widely used fixed ratio $(0.70)$ compared to the lower limit of normal are shown in Table 2.

Concordant obstructive cases (FEV1/FVC $<0.70$ \& $<$ LLN) showed a trend towards more severe airways obstruction than discordant obstructive cases $(\mathrm{FEV} 1 / \mathrm{FVC}<0.70$ \& $\geq$ LLN), see Table $3.89 .3 \%$ of discordant obstructive cases had a FEV1 greater than $70 \%$ of its predicted value, and none of the discordant obstructive cases had a FEV1 less than 50\% of its predicted value.

Overall, $6.4 \%(n=81)$ of the study population were discordant obstructive cases (FEV1/FVC $<0.70 \& \geq$ LLN) with mild to moderate obstructive impairment (FEV1 100$50 \%$ predicted). Concordant obstructive and discordant obstructive cases with mild to moderate impairment of FEV1 differed significantly in terms of age, gender, and reported cough and phlegm (see Table 4). However, when adjustments for age were made, they were very similar in terms of comorbid disease, smoking status, and reported dyspnea (see Table 4).

The clinical profile of subjects with discordant obstructive findings was similar to the profile of subjects with restrictive lung function (see Table 4). In addition to this, subjects with discordant obstructive findings (FEV1/FVC $<$ $0.70 \& \geq$ LLN) reported significantly more often a diagnosis of heart disease than subjects with "normal" lung function (FEV1/FVC $>0.70 \&$ FVC $\geq 80 \%$ pred.), see Table 4 .

\section{Discussion}

This population-based study contributes to the characterization of discordant obstructive cases (=subjects with "normal" findings using the LLN but abnormal findings using the fixed cutoff of $70 \%$ as a threshold for the FEV1/FVC ratio). The data suggest that subjects who are in between the two definitions of airways obstruction may not have

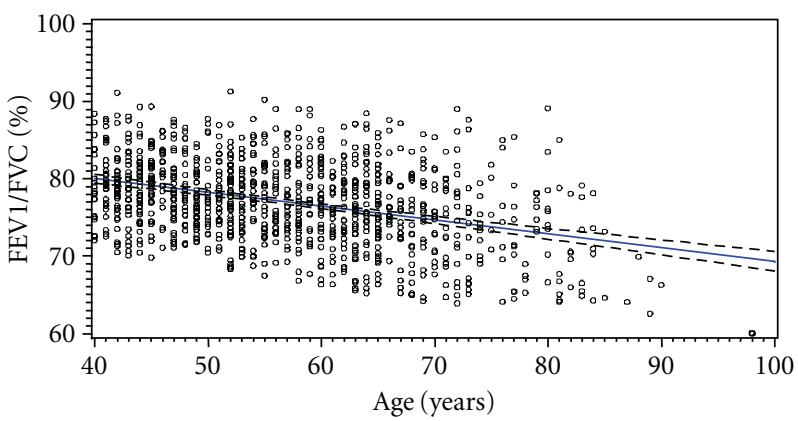

FIGURE 1: Study subjects with FEV1/FVC > LLN $(n=1059)$ : relationship between FEV1/FVC\% and age. Lines represent regression of FEV1/FVC ratio by age (solid line) with $95 \%$ confidence limits for mean predicted values (dotted lines). The horizontal line indicates the $70 \%$ level of the FEV1/FVC ratio.

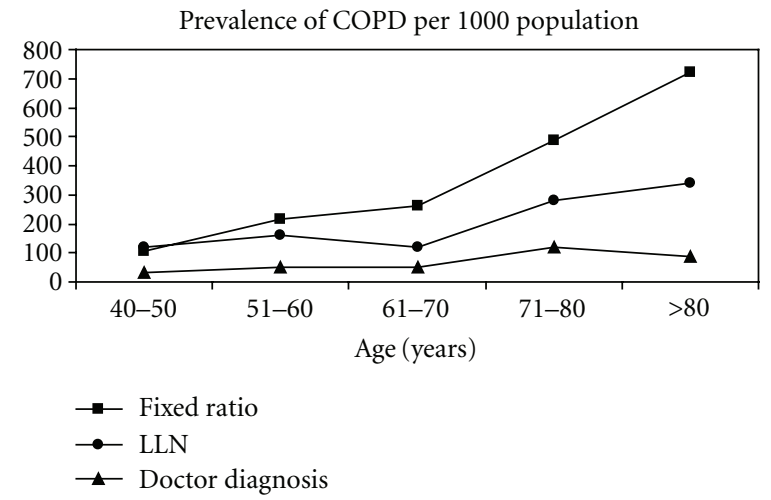

FIGURE 2: Prevalence of nonreversible airways obstruction with age, using different definitions (per 1000 population). "Fixed ratio": postbronchodilator FEV1/FVC < 0.70, "LLN": postbronchodilator FEV1/FVC < LLN, "doctor diagnosis": prior physicians diagnosis of COPD.

clinically significant airways obstruction. However, their clinical profile is characterized by relevant comorbid disease and is clearly different from the profile of age-matched subjects with "normal" lung function.

4.1. The Discrepancy between the Different Definitions. The discrepancy in the prevalence of airways obstruction depending on the criteria used to define disease is consistent with other studies.

A similar difference in the prevalence of COPD depending on the definition used was reported for adults aged 40 years and over in New Zealand, showing a GOLDdefined prevalence of COPD of $14.2 \%$ and a LLN-defined prevalence of $9.0 \%$ [8]. A recent study based on spirometry tests from a regional primary care diagnostic centre in the Netherlands has shown that the discrepancy between the two definitions for airflow obstruction increases along with age, and that utilization of the fixed FEV1/FVC cutoff may cause substantial COPD overdiagnosis in primary care [9]. In an elderly Chinese population (subjects aged 60 years and above), the prevalence of airways obstruction using the fixed 
TABLE 3: Severity of airways obstruction in concordant and discordant obstructive cases.

\begin{tabular}{|c|c|c|c|}
\hline Severity of airways obstruction & $\begin{array}{c}\text { Concordant obstructive cases }{ }^{\S} \\
(n=192)\end{array}$ & $\begin{array}{l}\text { Discordant obstructive } \\
\text { cases }^{\#}(n=112)\end{array}$ & $P$-value \\
\hline Possible normal variant (FEV1 $>100 \%$ predicted) & $22(11.4 \%)$ & $31(27.7 \%)$ & $<.001$ \\
\hline Mild obstruction (FEV1 70\%-100\% predicted) & $115(59.9 \%)$ & $69(61.6 \%)$ & $<.001$ \\
\hline Moderate obstruction (FEV1 50\%-70\% predicted) & $41(21.4 \%)$ & $12(10.7 \%)$ & .003 \\
\hline Severe obstruction (FEV1 < 50\% predicted) & $14(7.3 \%)$ & $0(0.0 \%)$ & l \\
\hline
\end{tabular}

${ }^{\S}$ Concordant obstructive cases: FEV1/FVC $<0.70 \&<$ LLN.

\#Discordant obstructive cases: FEV1/FVC $<0.70 \& \geq$ LLN.

TABLE 4: Characteristics of subjects with discordant obstructive findings and comparison to subjects with normal lung function, subjects with restrictive lung function and subjects with concordant obstructive findings. Presented obstructive cases are limited to those with mild to moderate impairment of FEV1 (FEV1 50\%-100\% pred.).

\begin{tabular}{|c|c|c|c|c|c|c|c|}
\hline & 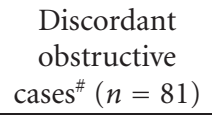 & $\begin{array}{l}\text { "Normal" lung } \\
\text { function\$ } \\
(n=414)\end{array}$ & $\begin{array}{l}\text { Restrictive lung } \\
\text { function }^{\Psi} \\
(n=82) \\
\end{array}$ & $\begin{array}{c}\text { Concordant } \\
\text { obstructive } \\
\text { cases }^{\S}(n=156)\end{array}$ & $P$-value* & $P$-value** & $P$-value $* * *$ \\
\hline \multicolumn{8}{|l|}{ Characteristics } \\
\hline Age, mean (SE) & $67(0.99)$ & $54.8(0.50)$ & $59.4(1.16)$ & $60.5(0.95)$ & $<.001$ & $<.001$ & $<.001$ \\
\hline Sex, male & $66(81.5 \%)$ & $230(55.6 \%)$ & $48(58.5 \%)$ & $76(48.7 \%)$ & $<.001$ & .002 & $<.001$ \\
\hline Never smoker & $33(40.7 \%)$ & $203(49.0 \%)$ & $35(42.7 \%)$ & $45(28.9 \%)$ & .172 & .802 & .065 \\
\hline \multicolumn{8}{|l|}{$\begin{array}{l}\text { Respiratory } \\
\text { Symptoms }\end{array}$} \\
\hline Cough & $14(17.3 \%)$ & $60(14.5 \%)$ & $19(23.2 \%)$ & $51(32.7 \%)$ & .796 & .291 & .009 \\
\hline Phlegm & $20(24.7 \%)$ & $88(21.3 \%)$ & $23(28.1 \%)$ & $65(41.7 \%)$ & .893 & .442 & .004 \\
\hline Dyspnea & $24(29.6 \%)$ & $62(15.0 \%)$ & $29(35.4 \%)$ & $41(26.3 \%)$ & .085 & .084 & .987 \\
\hline \multicolumn{8}{|l|}{ Comorbidities $^{\phi}$} \\
\hline Asthma & $7(8.6 \%)$ & $29(7.0 \%)$ & $5(6.1 \%)$ & $21(13.5 \%)$ & .116 & .172 & .585 \\
\hline Heart disease & $22(27.2 \%)$ & $30(7.3 \%)$ & $19(23.2 \%)$ & $23(14.7 \%)$ & .015 & .179 & .450 \\
\hline Hypertension & $33(40.7 \%)$ & $135(32.6 \%)$ & $29(35.4 \%)$ & $55(35.3 \%)$ & .223 & .970 & .689 \\
\hline Diabetes & $10(12.4 \%)$ & $32(7.7 \%)$ & $8(9.8 \%)$ & $10(6.4 \%)$ & .661 & .538 & .343 \\
\hline Stroke & $6(7.4 \%)$ & $6(1.5 \%)$ & $4(4.9 \%)$ & $3(1.9 \%)$ & .228 & .643 & .156 \\
\hline Tuberculosis & $2(2.5 \%)$ & $10(2.4 \%)$ & $2(2.4 \%)$ & $8(5.1 \%)$ & .479 & .929 & .195 \\
\hline \multicolumn{8}{|c|}{$\begin{array}{l}\text { "Discordant obstructive cases: FEV1/FVC }<0.70 \& \geq \mathrm{LLN} \text {. } \\
\text { \$Concordant obstructive cases: FEV1/FVC }<0.70 \&<\mathrm{LLN} \text {. } \\
\text { \$Normal lung function: FEV1/FVC }>0.70 \& \mathrm{FVC} \geq 80 \% \text { pred. } \\
\text { "Restrictive lung function: FEV1FVC }>0.70 \& \mathrm{FVC}<80 \% \text { pred. } \\
{ }^{\phi} \text { Results adjusted for age. } \\
{ }^{*} P \text {-value for difference between "discordant obstructive cases" and "normal lung function". } \\
* * P \text {-value for difference between "discordant obstructive cases" and "restrictive lung function". } \\
* * * P \text {-value for differences between "discordant obstructive cases" and "concordant obstructive }\end{array}$} \\
\hline
\end{tabular}

ratio of 0.70 or using the LLN for the postbronchodilator FEV1/FVC ratio was $25.9 \%$ and $12.4 \%$, respectively [10].

A population-based study in Norway using prebronchodilator spirometry data has shown that a FEV1/FVC ratio below 0.70 was $50 \%$ more frequent in women aged 70 years and above compared to women aged 60-69 years. The corresponding increase in men was $80 \%$. On the basis of their results, the authors suggested the use of a threshold of $65 \%$ $(\mathrm{FEV} 1 / \mathrm{FVC}<0.65)$ for subjects over the age of 70 years [11].

However, the discrepancy depending on the definition used shows that either the GOLD criteria lead to a relevant percentage of false positives or utilization of the lower limit of normal to a relevant percentage of false negatives.

In general, any diagnostic test should have both high sensitivity and high specificity. Since the FEV1/FVC ratio declines with age, the fixed ratio of 0.70 which is recommended by the GOLD Initiative, may lead to considerable overdiagnosis among healthy elderly people and underdiagnosis among young adults with early disease [3, 12-15]. The problem of misclassification might be pronounced in the primary care setting, where early stages of disease are seen. Therefore, utilization of the lower limit of normal instead 
of a fixed ratio has been especially recommended for COPD screening in primary care [16].

4.2. Pros and Cons of the Different Definitions. While utilization of the fixed ratio (0.70) is simple, convenient, and independent from the existence of adequate reference equations and specially adapted spirometers, the use of the age- and sex-specific LLN as a threshold for the FEV1/FVC ratio may lessen the risk of overdiagnosis of airways obstruction among the elderly and underdiagnosis among young adults.

Utilization of GOLD guidelines and unreflective interpretation of test results may have negative consequences by misclassifying healthy elderly subjects as COPD and thus possibly causing unnecessary treatment and healthcare costs. With this and other critical issues in mind, a growing number of experts recommend to replace the 0.70 threshold with the lower limit of normal threshold [17].

4.3. Discordant Obstructive Cases (In-Between Cases). When one definition of airways obstruction (FEV1/FVC $<$ LLN) is thought to replace another definition (FEV1/FVC $<0.70$ ) the main point of interest is of course the number and characteristics of those subjects who have discordant findings ("normal" using the LLN but "abnormal" using the fixed ratio).

The comparison of concordant obstructive (FEV1/FVC $<$ $0.70 \&<\mathrm{LLN}$ ) cases and discordant obstructive (FEV1/FVC $<$ $0.70 \& \geq \mathrm{LLN}$ ) cases revealed that subjects in the latter group were significantly older and significantly more likely to be male. In addition to this, discordant obstructive cases reported less active smoking and less respiratory symptoms. Our data suggest that utilization of the LNN as a threshold for the FEV1/FVC ratio helps to identify clinically significant disease.

However, the clinical profile of cases in between the two definitions (discordant obstructive cases FEV1/FVC $<0.70$ $\& \geq$ LLN) was characterized by high amounts of comorbid disease. When adjustments for age were made, subjects with discordant obstructive findings reported significantly more often a diagnosis of heart disease than subjects with normal lung function. The clinical profile of subjects with discordant obstructive findings was very similar to the profile of subjects with restrictive lung function. Therefore, this data suggest that a proportion of individuals with discordant obstructive findings may have clinically important comorbidities. Results of a cohort study of the Cardiovascular Health Study have shown that subjects classified as "normal" using the LLN but abnormal using the GOLD criteria (0.70) were more likely to die and to have a COPD-related hospitalization during followup. The authors suggested that a fixed ratio of less than 0.70 identifies at-risk patients, even among older adults [18]. In an editorial on the definition of COPD the author suggested that a finding that predicts a bad event or premature death may probably represent "disease" [19].

4.4. Definition of Airways Obstruction and Underdiagnosis. Besides the valuable discussion on what might be the most precise definition of airways obstruction, one has to take into consideration that currently the majority of disease is still undiagnosed and untreated. The prevalence of physician-diagnosed chronic airways obstruction in our study population was $5.6 \%$. This is far below both the prevalence defined by postbronchodilator FEV1/FVC $<0.70$ $(24.2 \%)$ and FEV1/FVC < LLN (15.3\%). A recent study in a primary care setting in Poland has shown that only $18.6 \%$ of subjects with COPD had previously been diagnosed [20]. Overall, about $8 \%-13 \%$ of people in general population surveys have airways obstruction without having a diagnosis of obstructive lung disease [21].

4.5. Limitations. Limitations of our study include the use of reference equations from the United States that may not ideally apply to our population. However, using either the NHANES III predictions or predictions based on the study sample gave the same high COPD prevalence [5]. Another potential limitation of our study is that $200 \mathrm{mcg}$ of salbutamol was administered instead of $400 \mathrm{mcg}$, as recommended by the GOLD guidelines. The prevalence of postBD airway obstruction would have been slightly lower with a higher dose of BD. However, many pulmonary function laboratories have been using $200 \mathrm{mcg}$ and we worried about the risk of arrhythmias in our field settings. The timing of the postbronchodilator spirometry only 15 minutes after the administration of salbutamol, while standard practice, may nonetheless underestimate the true bronchodilator response which may not be evident for 30-60 minutes.

\section{Conclusion}

The lower limit of normal (LLN) seems to be the more reasonable threshold to define clinically significant airways obstruction. The risk of substantial overdiagnosis of COPD and subsequent unnecessary treatment and healthcare costs (due to utilization of a simple fixed threshold) is pitted against the reasonable desire for simplicity.

The results of this study indicate that subjects who are in between the two definitions of airways obstruction (discordant obstructive cases, FEV1/FVC $<0.70 \& \geq$ LLN) do not have clinically significant airways obstruction. However, their clinical profile is characterized by relevant comorbid disease and, therefore, they might be at risk and should be followed carefully.

\section{Funding}

The sponsors of the study had no role in study design, data collection, data analysis, data interpretation, writing of the report, or the decision to submit for publication.

\section{Authors Contribution}

B. Lamprecht has been responsible for data collection, data analysis and writing the aper. L. Schirnhofer has been responsible for data collection and helped to revise the paper. B. Kaiser has been responsible for data analysis and helped to revise the paper. S. A. Buist was involved in writing and 
revising the paper. D. M. Mannino was involved in writing and revising the paper. $M$. Studnicka was involved in writing and revising the paper.

\section{Conflict of Interests}

B. Lamprecht has no conflicts of interest to disclose. L. Schirnhofer has no conflicts of interest to disclose. B. Kaiser has no conflicts of interest to disclose. S. A. Buist has served on advisory boards for GlaxoSmithKline, ALTANA, Schering Plough, Merck, Schering Plough, Novartis, Pfizer, and Sepracor and donates most of her honoraria to the ATS; has participated in COPD workshops funded by AstraZeneca and GlaxoSmithKline and is scientific director for the Burden of Obstructive Lung Disease (BOLD) Initiative that receives unrestricted educational grants to the Kaiser Permanente Center for Health Research from GSK, Pfizer, Boehringer Ingelheim, AstraZeneca, ALTANA, Novartis, Merck, Chiesi, Schering Plough, and Sepracor. D. M. Mannino has received research funding from GlaxoSmithKline, Pfizer, and Novartis and has served as a consultant or speaker for GlaxoSmithKline, Pfizer, Boerhringer-Ingelheim, Novartis, Astra-Zeneca, Dey, and Sepracor. He has also served as an expert witness in cases involving exposure to secondhand smoke and diacetyl. M. Studnicka has no conflicts of interest to disclose.

\section{Acknowledgments}

The BOLD project in Salzburg, Austria, was funded by unrestricted Grants from Altana; Astra-Zeneca; BoehringerIngelheim; GlaxoSmithKline; Merck, Sharpe, and Dohme; Pfizer; Novartis. GlaxoSmithKline also provided in-kind contributions. The paper was supported by the "Salzburger Gebietskrankenkasse" (local public health insurance) and the local government of Salzburg.

\section{References}

[1] G. Viegi, F. Pistelli, D. L. Sherrill, S. Maio, S. Baldacci, and L. Carrozzi, "Definition, epidemiology and natural history of COPD," European Respiratory Journal, vol. 30, no. 5, pp. 9931013, 2007.

[2] K. F. Rabe, S. Hurd, A. Anzueto et al., "Global strategy for the diagnosis, management, and prevention of chronic obstructive pulmonary disease: GOLD executive summary," American Journal of Respiratory and Critical Care Medicine, vol. 176, no. 6, pp. 532-555, 2007.

[3] J. A. Hardie, A. S. Buist, W. M. Vollmer, I. Ellingsen, P. S. Bakke, and O. Mørkve, "Risk of over-diagnosis of COPD in asymptomatic elderly never-smokers," European Respiratory Journal, vol. 20, no. 5, pp. 1117-1122, 2002.

[4] R. Pellegrino, G. Viegi, V. Brusasco et al., "Interpretative strategies for lung function tests," European Respiratory Journal, vol. 26, no. 5, pp. 948-968, 2005.

[5] L. Schirnhofer, B. Lamprecht, W. M. Vollmer et al., "COPD prevalence in Salzburg, Austria: results from the Burden of Obstructive Lung Disease (BOLD) study," Chest, vol. 131, no. 1, pp. 29-36, 2007.

[6] American Thoracic Society Statement, "Standardization of spirometry, 1994 update," American Journal of Respiratory and Critical Care Medicine, vol. 152, pp. 1107-1136, 1995.
[7] J. L. Hankinson, J. R. Odencrantz, and K. B. Fedan, "Spirometric reference values from a sample of the general U.S. Population," American Journal of Respiratory and Critical Care Medicine, vol. 159, no. 1, pp. 179-187, 1999.

[8] P. Shirtcliffe, M. Weatherall, S. Marsh et al., "COPD prevalence in a random population survey: a matter of definition," European Respiratory Journal, vol. 30, no. 2, pp. 232-239, 2007.

[9] T. R. J. Schermer, I. J. M. Smeele, B. P. A. Thoonen et al., "Current clinical guideline definitions of airflow obstruction and COPD overdiagnosis in primary care," European Respiratory Journal, vol. 32, no. 4, pp. 945-952, 2008.

[10] F. W. S. Ko, J. Woo, W. Tam et al., "Prevalence and risk factors of airflow obstruction in an elderly Chinese population," European Respiratory Journal, vol. 32, no. 6, pp. 1472-1478, 2008.

[11] A. Medbø and H. Melbye, "Lung function testing in the elderly-can we still use FEV/FVC $<70 \%$ as a criterion of COPD?" Respiratory Medicine, vol. 101, no. 6, pp. 1097-1105, 2007.

[12] E. Hnizdo, H. W. Glindmeyer, E. L. Petsonk, P. Enright, and A. S. Buist, "Case definitions for chronic obstructive pulmonary disease," Journal of Chronic Obstructive Pulmonary Disease, vol. 3, no. 2, pp. 95-100, 2006.

[13] I. Cerveri, A. G. Corsico, S. Accordini et al., "Underestimation of airflow obstruction among young adults using FEV FVC < $70 \%$ as a fixed cut-off: a longitudinal evaluation of clinical and functional outcomes," Thorax, vol. 63, no. 12, pp. 1040-1045, 2008.

[14] A. C. W. Lau, M. S. M. Ip, C. K. W. Lai et al., "Variability of the prevalence of undiagnosed airflow obstruction in smokers using different diagnostic criteria," Chest, vol. 133, no. 1, pp. 42-48, 2008.

[15] S. D. Roberts, M. O. Farber, K. S. Knox et al., "FEV/FVC ratio of $70 \%$ misclassifies patients with obstruction at the extremes of age," Chest, vol. 130, no. 1, pp. 200-206, 2006.

[16] T. R. J. Schermer and P. H. Quanjer, "COPD screening in primary care: who is sick?" Primary Care Respiratory Journal, vol. 16, no. 1, pp. 49-53, 2007.

[17] R. Pellegrino, V. Brusasco, G. Viegi et al., "Definition of COPD: based on evidence or opinion?" European Respiratory Journal, vol. 31, no. 3, pp. 681-682, 2008.

[18] D. M. Mannino, A. S. Buist, and W. M. Vollmer, "Chronic obstructive pulmonary disease in the older adult: what defines abnormal lung function?" Thorax, vol. 62, no. 3, pp. 237-241, 2007.

[19] D. M. Mannino, "Defining chronic obstructive pulmonary disease... and the elephant in the room," European Respiratory Journal, vol. 30, no. 2, pp. 189-190, 2007.

[20] M. Bednarek, J. Maciejewski, M. Wozniak, P. Kuca, and J. Zielinski, "Prevalence, severity and underdiagnosis of COPD in the primary care setting," Thorax, vol. 63 , no. 5 , pp. $402-$ 407, 2008.

[21] J. Zielinski, M. Bednarek, D. Górecka et al., "Increasing COPD awareness," European Respiratory Journal, vol. 27, no. 4, pp. 833-852, 2006. 


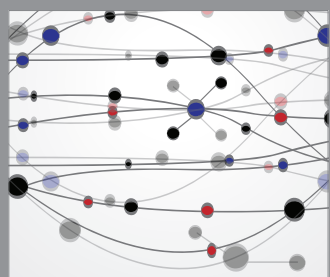

The Scientific World Journal
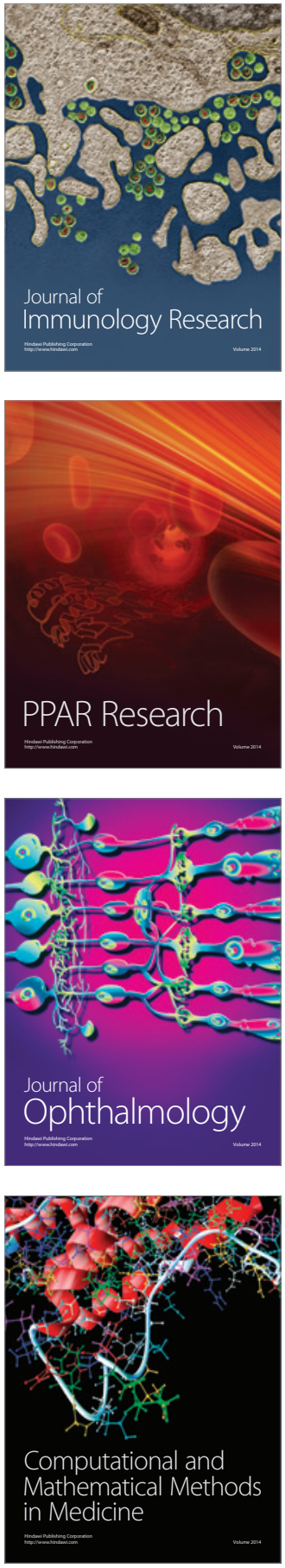

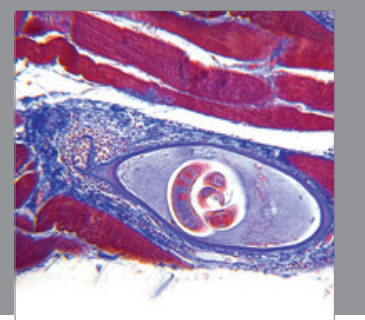

Gastroenterology

Research and Practice
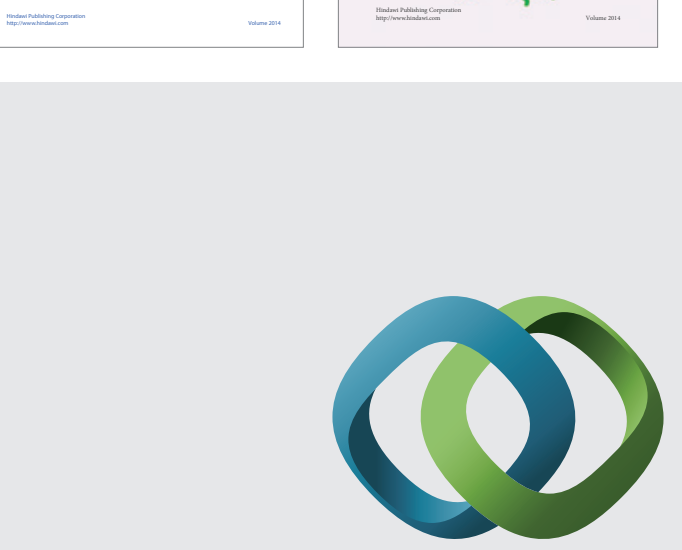

\section{Hindawi}

Submit your manuscripts at

http://www.hindawi.com
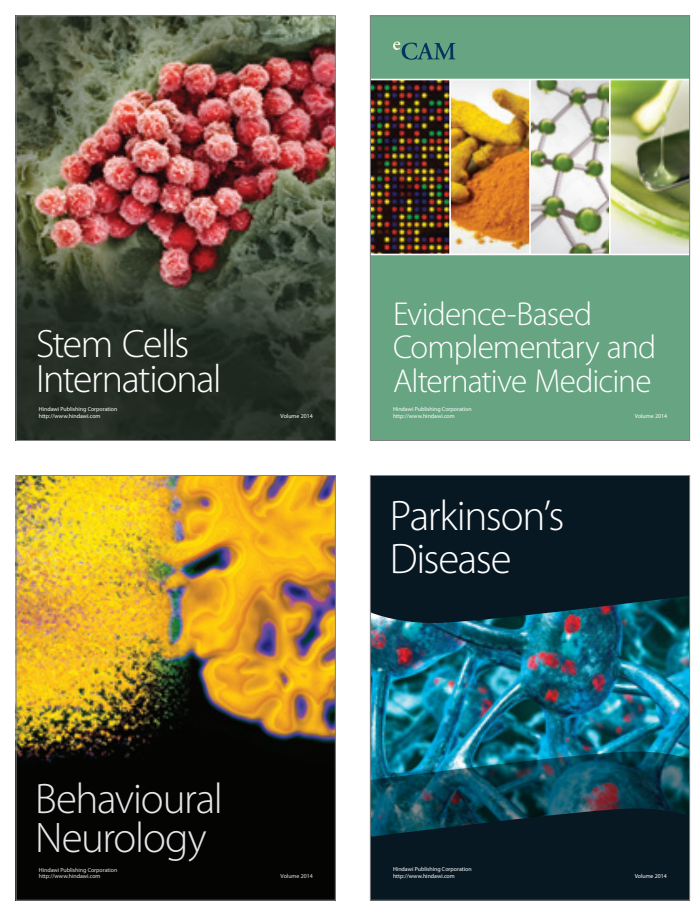

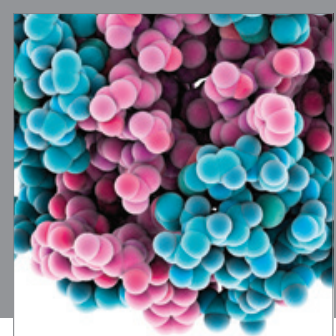

Journal of
Diabetes Research

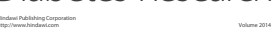

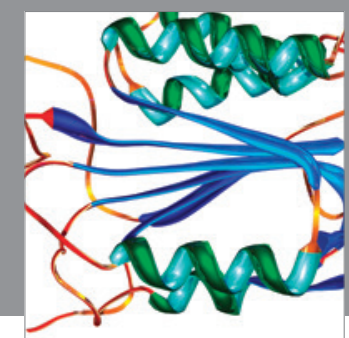

Disease Markers
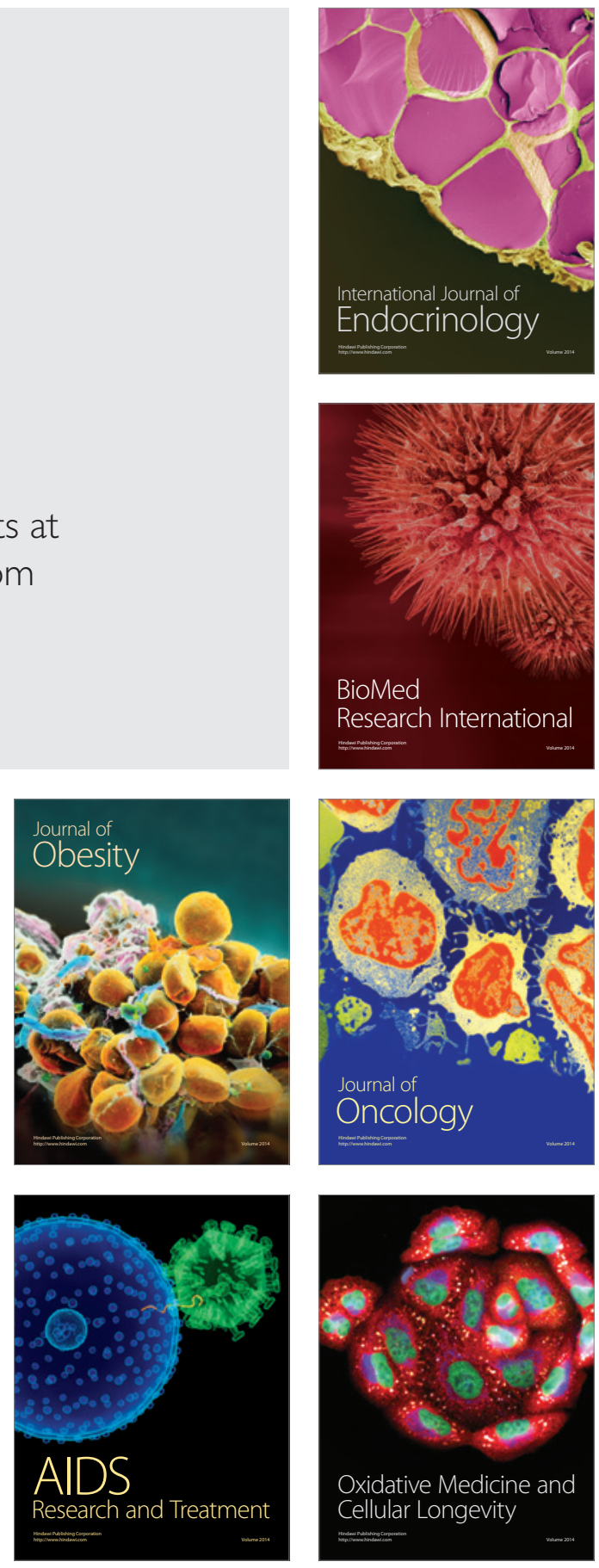